\title{
Adıgüzel Hydroelectric Power Plant Modeling and Load-Frequency Control
}

\author{
${ }^{1}$ Yüksel Oğuz ${ }^{* 1}$ Ahmet Kaysal and ${ }^{1}$ Kübra Kaysal \\ ${ }^{* 1}$ Faculty of Engineering, Department of Electric \& Electronic Engineering, Afyon Kocatepe University, Turkey
}

\begin{abstract}
In this study, to realize the load-frequency control according to various loading statuses, modeling of dynamic behaviour of the Adigüzel Hydroelectric Power Plant (HEPP) was carried out by using the Matlab/Simulink program. By establishing the dynamic model of 36MVA synchronous generator and other components in the system in a manner reflecting its behavior in the real system, performance of PID controller in speed regulator circuit was examined according to various load statuses. In the simulation studies, it has been observed that oscillations in voltage and frequency remain within acceptable tolerance limits in a short time like 2-4 seconds depending on various load statuses and HEPP comes to stable state.
\end{abstract}

Keywords: Hydroelectric Power Plant, Dynamic Model, PID Controller, Load-Frequency Control.

\section{Introduction}

Since the industrial revolution, mechanization has increased rapidly in parallel to the need of electric energy. As the electric energy has been mostly met by electric power satiations that use fossil fuels, rapid decrease has occurred in energy sources. Besides, because of the problem that electric energy cannot be stored in great amounts, it becomes obligatory to both generate electric energy in amounts capable of meeting current demands and in higher efficiency and to prefer renewable energy sources as an energy source [1]. Today, changes in supply and demand, desire for economical generation, increasing environmental responsibility and necessity for mains frequency to be constant or in a value close to constant to ensure sufficient operation conditions clearly suggest the importance of control concept in power systems [2].

In interconnected power systems, the primary purpose of controlling the system is to keep the power system in normal working status. Normal working status in general means that in the power system all the instant load demands are met, active and reactive power balance is protected, frequency and bar voltages are kept constant in nominal values and there exists no excessively loaded element in the system. Active power balance of interconnected system is ensured by making the generation amounts of synchronous generators that are connected to the system sensitive to changing system frequency. In normal condition, the difference between output powers of generators connected to the system and instant load causes change in nominal frequency of the system. If the generation amount is more than the demanded power, speeds and so, frequencies of generators increase; if the generation amount is less than the demanded power, frequency decreases. In case of deviation, bringing of frequency to desired value is ensured by controlling the speed of turbine encompassing the generator. For this operation, an integral (I) is used in general and by adjusting the integral gain of controller, steady state error of frequency is minimized [3].

Because of importance of the load frequency and as existing systems have to react to such problems as fast as possible, many studies have been made on this subject. Culberg and colleagues showed in their study, a single area hydro-turbine generator system frequency for the inspection found fuzzy inference based controller will have designed and developed controller and the traditional PID controller and the benchmark has been carried out [4]. With respect to Özbay and Gençoğlu (2011), in their study on the hydroelectric power plant load frequency control by using Matlab/Simulink program the turbine, generator and regulator have created models. Linear and nonlinear models in hydroelectric power plant

*Corresponding author: Faculty of Engineering, Department of Electric \& Electronic Engineering Afyon Kocatepe University, Afyonkarahisar TURKEY. E-mail address: akaysal@aku.edu.tr, Phone: +902723530913 Fax: $+902723530914$ 
turbine, for different load-time and frequency-time changes in power have achieved [5]. Yalçın et al. (2010) realized controlling of four quadrant power system with PID controller and examined its performance. They compared the four quadrant power system they designed to one guardant and two quadrant power systems. Besides, they proved with analysis results that PID controller gave a better result in comparison to PI controller in terms of time of settlement and maximum deterioration value [1]. Wu Dongsheng et al. (2011) designed an algorithm depended on optimization of particle packs developed to overcome deficiencies of PID controller. So, gain coefficients of PID controller used in control of DC motor were determined with this algorithm. The developed controller was compared to conventional PID controller and the simulation results indicated that it was better [6].

In this study, a dynamic behaviour model of the Adıgüzel HEPP was established and performance of PID controller according to various loading statutes was examined. With the analysis results, it has been determined that by minimizing oscillations in voltage and frequency in a short time like 2-4 seconds, it comes to steady state.

\section{Materials and Method}

Arising from the structure of synchronous generators speed-frequency and excitation current and voltage relationships have been developed on the basic of two control loop.

\section{i. Frequency Control \\ ii. Voltage Control}

Interconnected power system, load frequency control (LFC) and automatic voltage regulator (AVR) equipment are installed for each generator. Fig. 1 represents the schematic diagram of the LFC and the AVR loop. The controllers are set for a particular operating condition and take care of small changes in load demand to maintain the frequency and voltage magnitude within the specified limits. Small changes in real power are mainly dependent on changes in rotor angle. The reactive power is mainly dependent on the voltage magnitude [7].

In this diagram, kinetic energy of the water is converted to mechanical power or moment by the hydraulic turbine model. Inputs of the synchronous generator model are mechanical energy obtained from the hydraulic turbine, voltage at network or tips of load and frequency magnitudes. Outputs of synchronous generator are network or active and reactive power values necessary for the load. Voltage and frequency of synchronous generator can also be expressed as output magnitudes in the hydroelectric power generation systems that operate in isolation to electric networks.

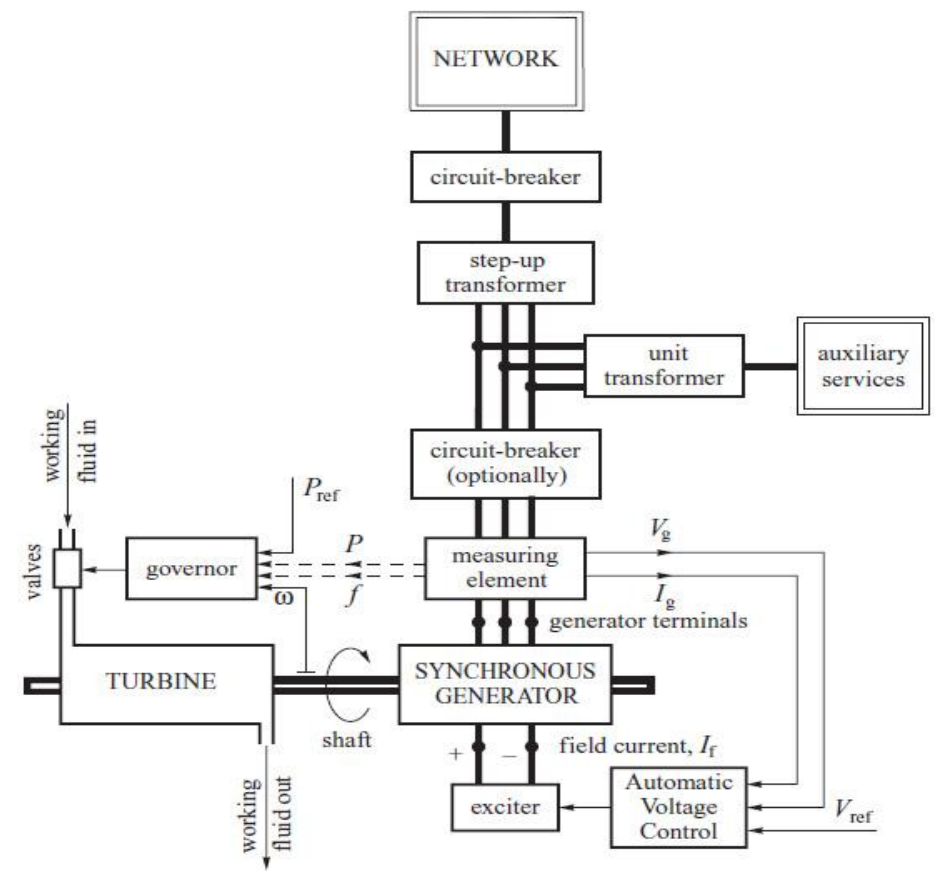

Figure 1. Block diagram of a power generation unit [8]. 


\subsection{Hydroelectric Power Plant Components and Model}

In this paper, for modeling of hydraulic system, it is considered its classical transfer function. For such deduction, the following assumptions are taken:

1. The hydraulic resistance is negligible,

2. Inelastic penstock pipe and incompressible water,

3. Velocity of water varies directly with gate opening and with the square root of the net head,

4. Turbine output power is proportional to the product of head and volume flow.

Based on that, turbine and penstock characteristics are determined by three basic equations:

$$
\begin{gathered}
U=K_{u} G \sqrt{H} \\
P_{m}=K_{p} H U \\
\frac{d U}{d t}=-\frac{a_{g}}{L} \Delta H
\end{gathered}
$$

(1), (2) and (3) represent respectively the velocity of water, the turbine mechanical power and the acceleration of water column.

Where; $U$ : Water velocity, $G$ : Ideal gate opening, $H$ : Hydraulic head at gate, $P_{m}$ : Turbine mechanic power, $L$ : Length of conduit, $a_{g}$ : Acceleration due to gravity, $t$ : Time in seconds, $K_{u}, K_{p}$ : Constant of proportionality.

Linearizing by considering small displacement, and normalizing (1), (2) and (3) by initial steady-state values, it is obtained the following equation:

$$
G_{T}(s)=\frac{1-T_{w} s}{1+\frac{1}{2} T_{w} s}
$$

That is the "classical" transfer function of a hydraulic turbine, where $T_{w}$ is the water starting time at rated load. It shows how the turbine power output changes in response to a change in gate opening for an ideal lossless turbine. This linear model represents the small signal performance of the turbine providing insights into the basic characteristics of the hydraulic systems [2, 9-10]. The generator model and load model are given in Eq. 5-6.

$$
\begin{aligned}
\Delta \Omega(s)\left(\frac{d \Delta \omega}{d t}\right) & =\frac{1}{2 H s}\left[\Delta P_{m}(s)-\Delta P_{e}(s)\right] \\
\Delta P_{e} & =\Delta P_{L}+D \Delta w
\end{aligned}
$$

Where; $P_{m}$ : Turbine mechanical power, $P_{e}$ : Generator electrical power, $H$ : Inertia constant, $\delta$ : Electrical power angle, $w$ : Electrical angular velocity, $\Delta P_{L}$ : Nonfrequency-sensitive load change, $D \Delta w$ : Frequency-sensitive load change.

When the generator electrical load is suddenly increased, the electrical power exceeds the mechanical power input. This power deficiency is supplied by the kinetic energy stored in the rotating system. The reduction in kinetic energy causes the turbine speed and consequently, the generator frequency to fall. The change in speed is sensed by the turbine governor which acts to adjust the turbine input valve to change the mechanical power output to bring the speed to a new steady-state.

For stable operation, the governors are designed to permit the speed to drop as the load is increased. The steady-state characteristic of such a governor is shown in Fig. 2. The slope of the curve represents the speed regulation $R$. Governors typically have a speed regulation of 5-6 percent from zero to full load. The speed governor mechanism acts as a comparator whose output $\Delta P_{g}$ is the difference between the reference set power $\Delta P_{\text {ref }}$ and the power $\frac{1}{R} \Delta w$ as given from the governor speed characteristics are given in Eq. 7-8.

$$
\begin{gathered}
\Delta P_{g}=\Delta P_{\text {ref }}-1 /{ }_{R} \Delta w \\
\Delta P_{V}(s)=\frac{1}{1+\tau_{g}} \Delta P_{g}(s)
\end{gathered}
$$




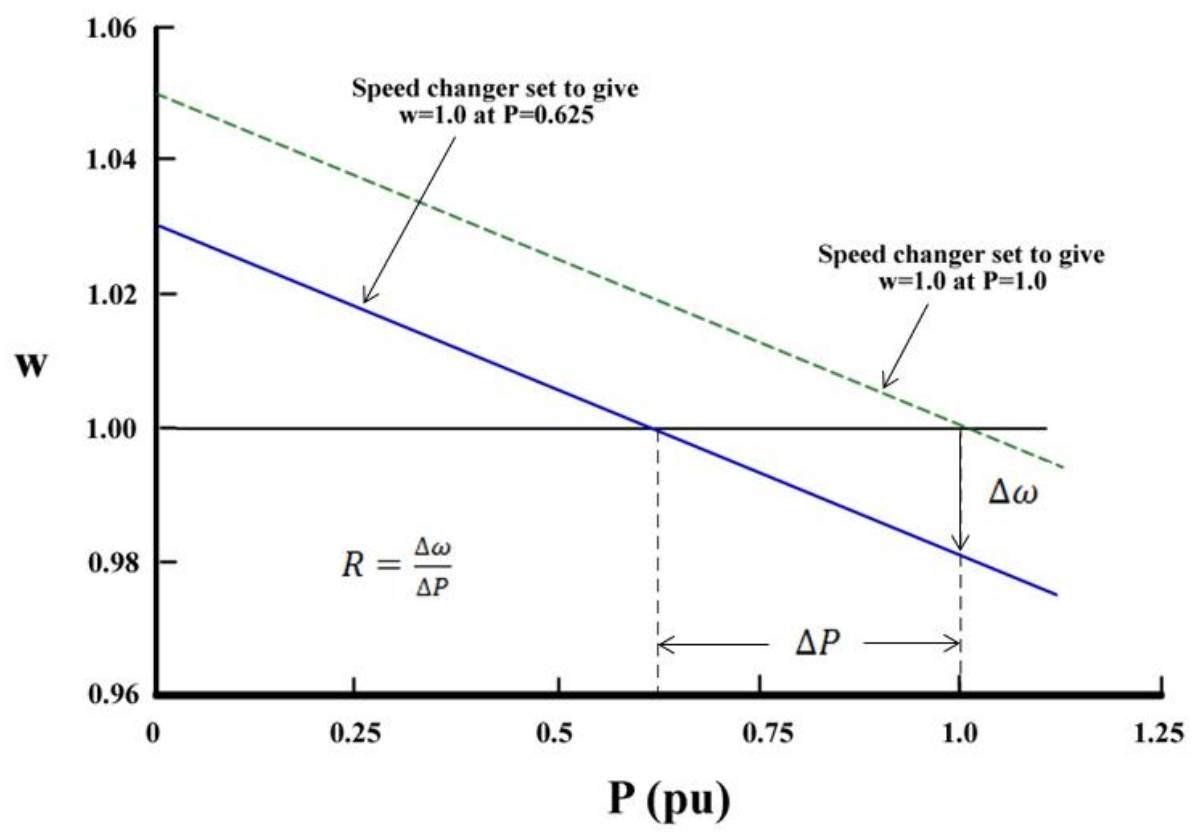

Figure 2. Steady-state frequency-power relation for a turbine governor [7].

As the power systems are nonlinear, in load frequency controls made with PID controllers, adaptation to any load change cannot be fast enough and lasting frequency error cannot be decreased to zero. Besides, as long as the number of quadrants increases, controlling of them becomes more difficult [1]. The dynamic model of the PID controller that is one of the widely used controller types in today's industry was used in the established hydroelectric power system and its performance was examined. The PID controller is given in Eq. 9 in its most general expression.

$$
u(t)=K\left(e(t)+\frac{1}{T_{I}} \int_{0}^{t} e(t) d t+T_{d} \frac{d e(t)}{d t}\right)
$$

PID gain coefficients of the PID controller of speed regulator according to various loading statutes for the voltage frequency control and mechanic power (pu), the position of adjustment wings controlled by the speed regulator and power values at output of the system are given in Table 1. The gain coefficients of the PID controller used in this study were determined for each loading status in range of $\left(K_{P}, K_{I}, K_{D}\right), 0.1 \mathrm{pu}$ and $1.0 \mathrm{pu}$.

Table 1. PID Gain coefficients

\begin{tabular}{cccccc}
\hline $\boldsymbol{P}_{\boldsymbol{m e k}}$ & Gate & $\boldsymbol{P}_{\boldsymbol{e l k}}$ & $\boldsymbol{K}_{\boldsymbol{P}}$ & $\boldsymbol{K}_{\boldsymbol{I}}$ & $\boldsymbol{K}_{\boldsymbol{D}}$ \\
\hline 0,1 & 0,0965 & 3,1825 & 0,00558537 & 0,00000080 & 8,5467000568 \\
0,2 & 0,1930 & 6,7897 & 0,01124169 & 0,00000331 & 8,4482199936 \\
0,3 & 0,2896 & 10,4070 & 0,25623287 & 0,01780566 & $-2,4179942742$ \\
0,4 & 0,3861 & 14,0375 & 0,71591296 & 0,04657833 & $-3,2007578307$ \\
0,5 & 0,4826 & 17,6865 & 0,88054668 & 0,06950864 & $-3,0580565336$ \\
0,6 & 0,5791 & 21,3600 & 1,07148533 & 0,09612619 & $-2,5605848591$ \\
0,7 & 0,6756 & 25,0640 & 1,21479695 & 0,14046803 & $-0,8917655191$ \\
0,8 & 0,7721 & 28,8000 & 1,46073222 & 0,18331606 & 0 \\
0,9 & 0,8687 & 32,5800 & 1,99686681 & 0,14315631 & $-1,2251305837$ \\
1,0 & 0,9652 & 36,4000 & 1,26943876 & 0,18692192 & 0 \\
\hline
\end{tabular}


We used in the model of hydroelectric power generation system block diagrams are given in Fig. 3 .

\subsection{Adıgüzel Hydroelectric Power Plant}

The Adigüzel HEPP, which is one of the construction of Büyük Menderes River Basin, developed by General Directorate of State Hydraulic Works of Turkey (D.S.I) for the purposes of power generation, irrigation and flood control. The Adigüzel HEPP consists of a rock fill dam of $140 \mathrm{~m}$. in height above foundation to create a reservoir with a storage capacity of 1100 million $\mathrm{m}^{3}$ and HEPP of $2 \times 36 \mathrm{MVA}$ installed capacity to provide an annual energy production of 280 million $\mathrm{kWh}$.

Each generator is three phase $50 \mathrm{~Hz}, 13.8 \mathrm{kV}$ phase to phase at generator terminals. It is capable of delivering the full rated MVA at rated power factor and frequency through a range of 5 percent below, 5 percent above the rated voltage $13.8 \mathrm{kV}$ in balanced phase distribution.

As it can be seen Fig. 4, dynamic modeling of the hydroelectric power generation system in conformity with its behavior in real time was realized by using the SimPowerSystems in the Matlab/Simulink program. The block diagrams given in Fig. 5 are the compounds that belong to the Adigüzel HEPP. These block diagrams consist of hydraulic turbine and speed regulator, warning system, synchronous generator and power transformer.

\section{Results}

The simulation results of generation and consumption powers of 36MVA hydroelectric power generation system whose installation and simulation was made according to various loading conditions were given separately and analyzed.

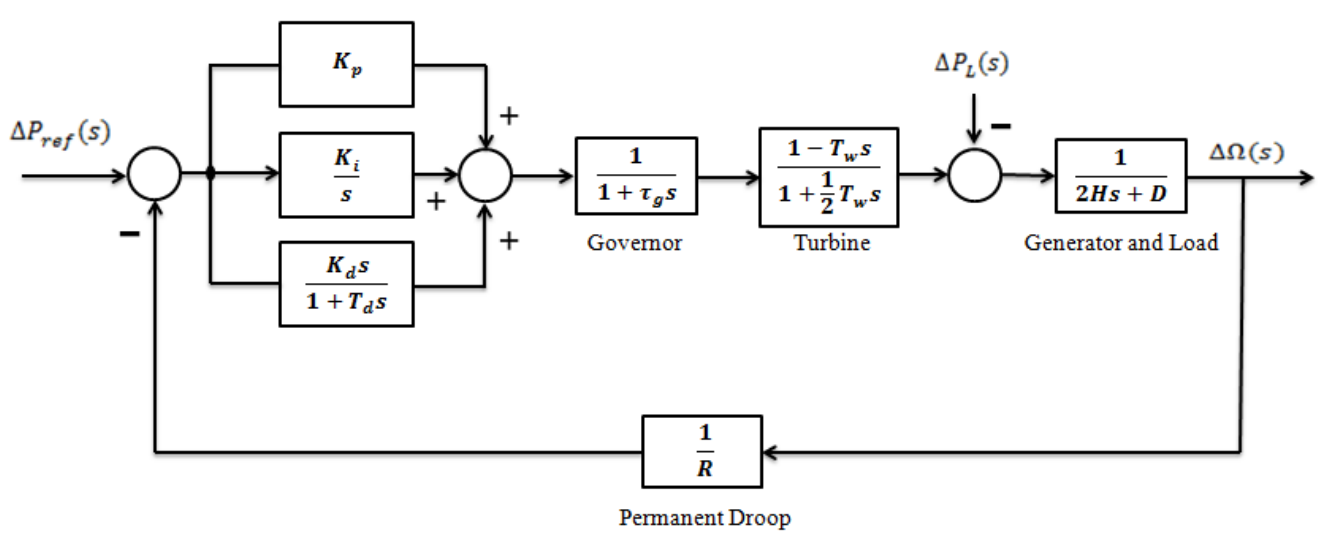

Figure 3. Load-frequency control block diagram of hydroelectric power generation system.
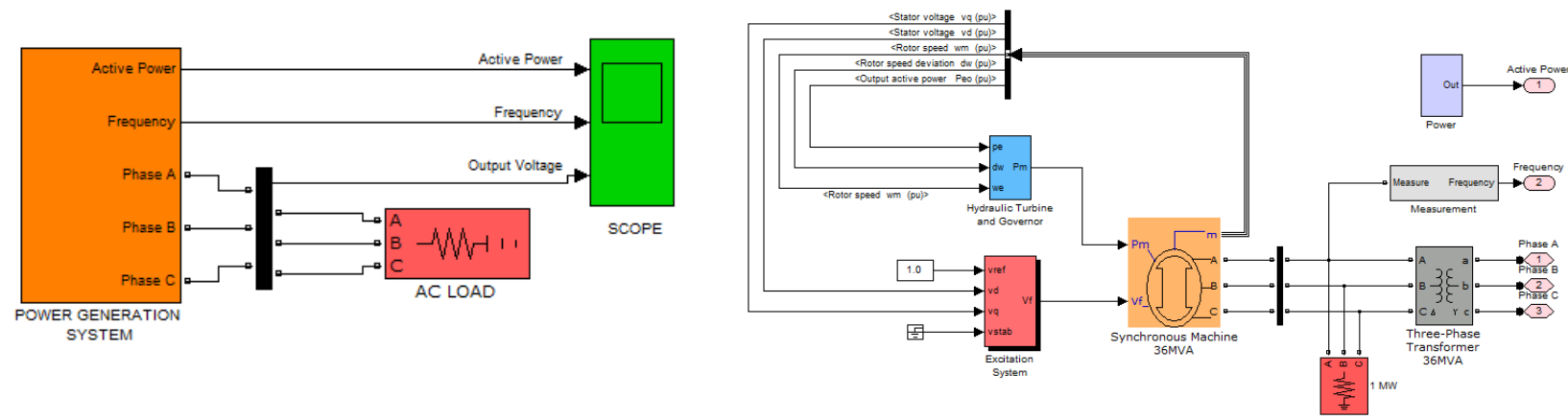

Figure 4. Simulation block diagram of Hydroelectric power generation system.

Figure 5. Simulation block diagrams of HEPP components. 

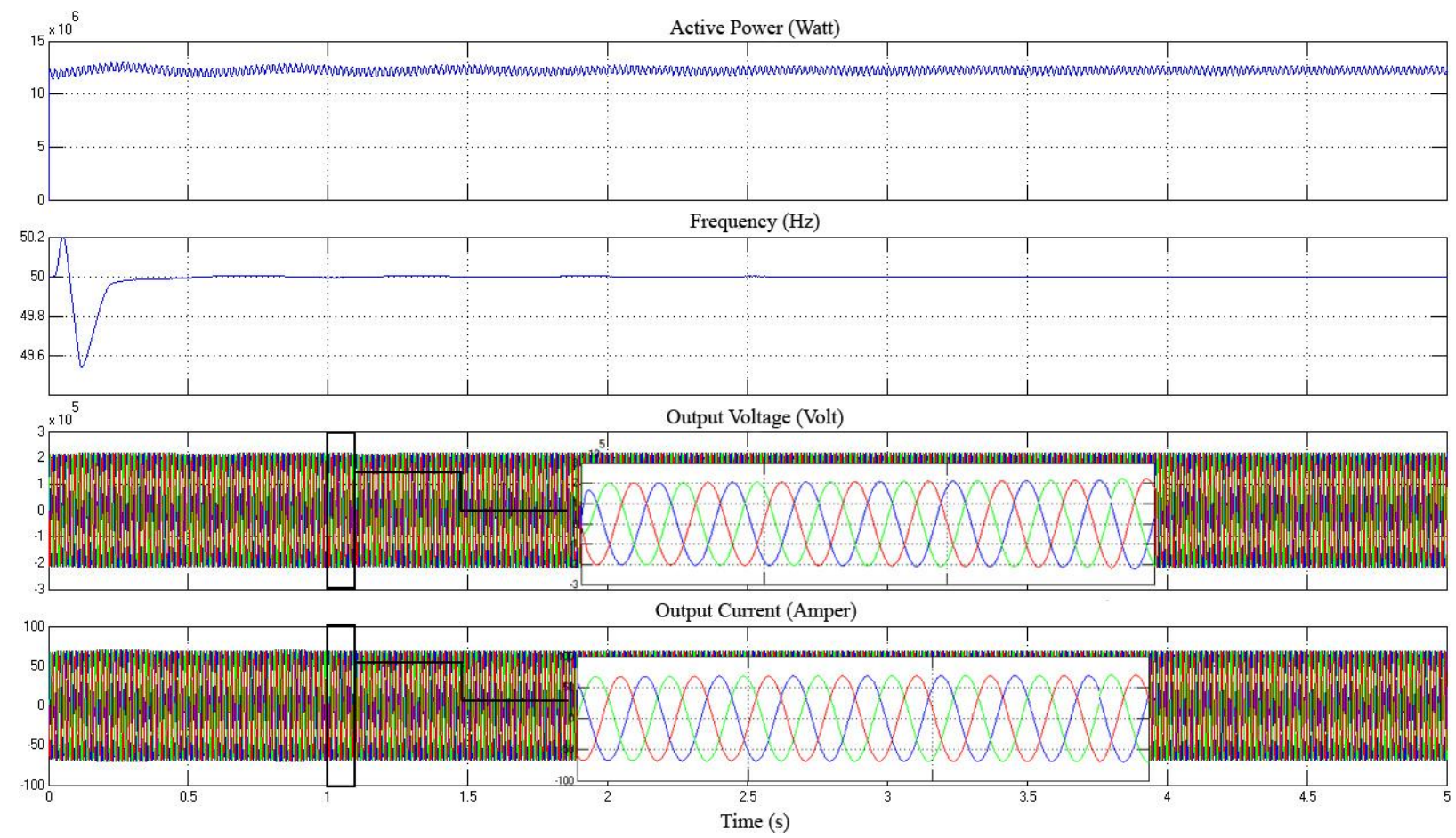

Figure 5. Change in electrical output magnitudes when loaded with HEPP 12MW $(0,4 \mathrm{pu})$
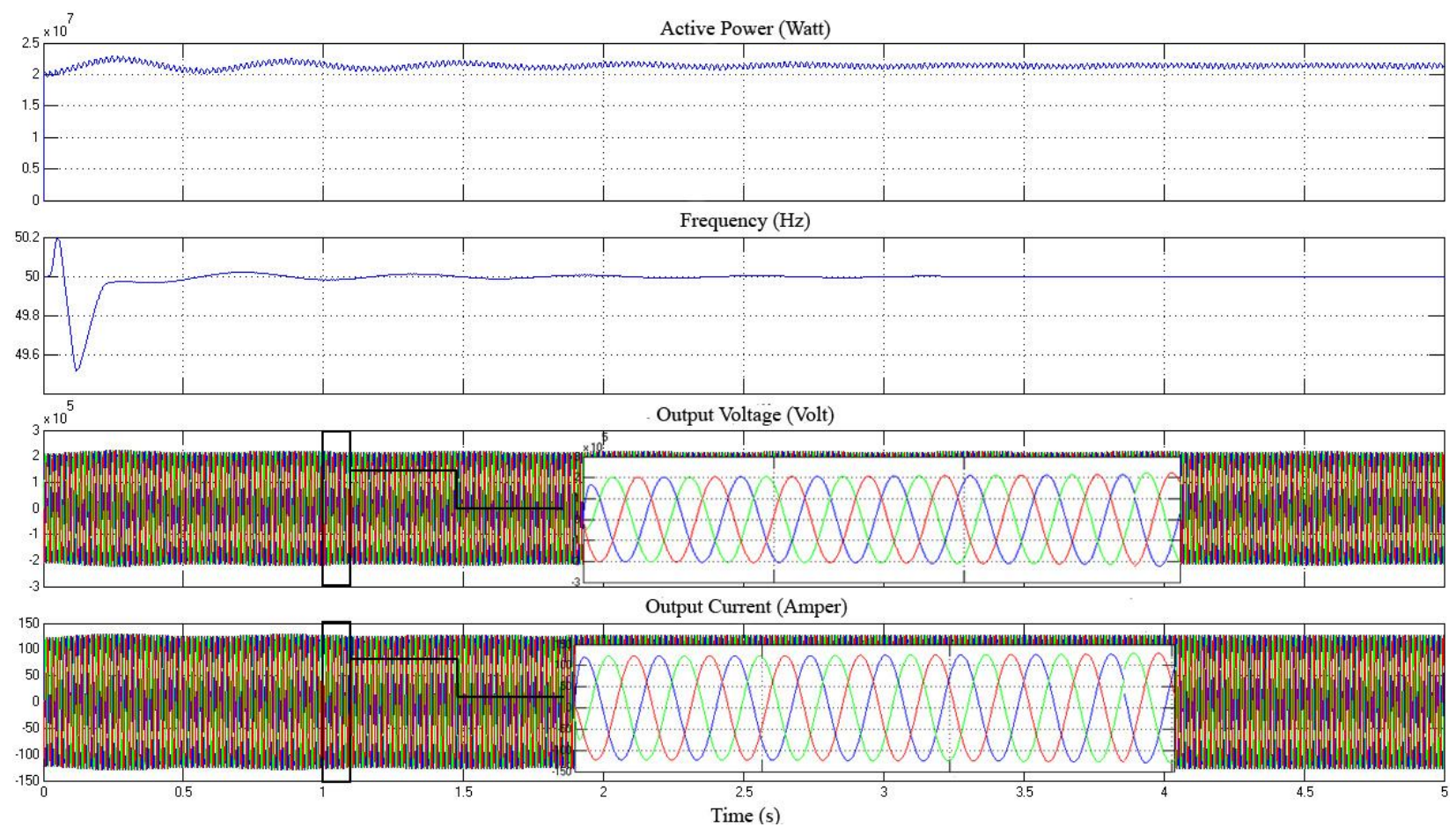

Figure 6. Change in electrical output magnitudes when loaded with $\operatorname{HEPP} 21 \mathrm{MW}(0,7 \mathrm{pu})$.

Graphics in Fig. 6 indicate which has taken from the synchronous generator terminals of total load of about $12 M W(0,4 p u)$, in system frequency within the desired limits, the effective terminal voltage is $V_{e t}=153,4 \mathrm{kV}\left(V_{\max }=217 \mathrm{kV}\right)$ and the effective load current is $I_{e t}=48,8 \mathrm{~A}\left(I_{\max }=69 \mathrm{~A}\right)$. It is clear 
from given graphics that it was loaded with HEPP $12 \mathrm{MW}$ load and came to stable state with minimization of oscillations in voltage and frequency in a short time like 1-2 seconds.

Graphics in Fig. 7 indicate total load of the synchronous generator terminals of about $21 M W(0,7 p u)$, system frequency with in the desired tolerance limits, the effective terminal voltage is $V_{e t}=152,7 \mathrm{kV}\left(V_{\max }=216 \mathrm{kV}\right)$ and the effective load current is $I_{e t}=90 \mathrm{~A}\left(I_{\max }=127 \mathrm{~A}\right)$. By looking to graphics, that it was loaded with HEPP $21 M W$ load and came to stable state with minimization of oscillations in voltage and frequency in a short time like 2-3 seconds.

Graphics in Fig. 8 indicate according to the total load that is taken from the terminals of the synchronous generator is $30,6 M W(1,0 p u)$, the system frequency within the desired tolerance, the effective terminal voltage is $V_{e t}=151,7 \mathrm{kV}\left(V_{\max }=214,5 \mathrm{kV}\right)$ and the effective load current is $I_{e t}=130,8 A\left(I_{\max }=\right.$ $185 A$ ). It is shown by graphic that it was loaded with HEPP $30,6 M W$ load and came to stable state with minimization of oscillations in voltage and frequency in a short time like 3-4 seconds.
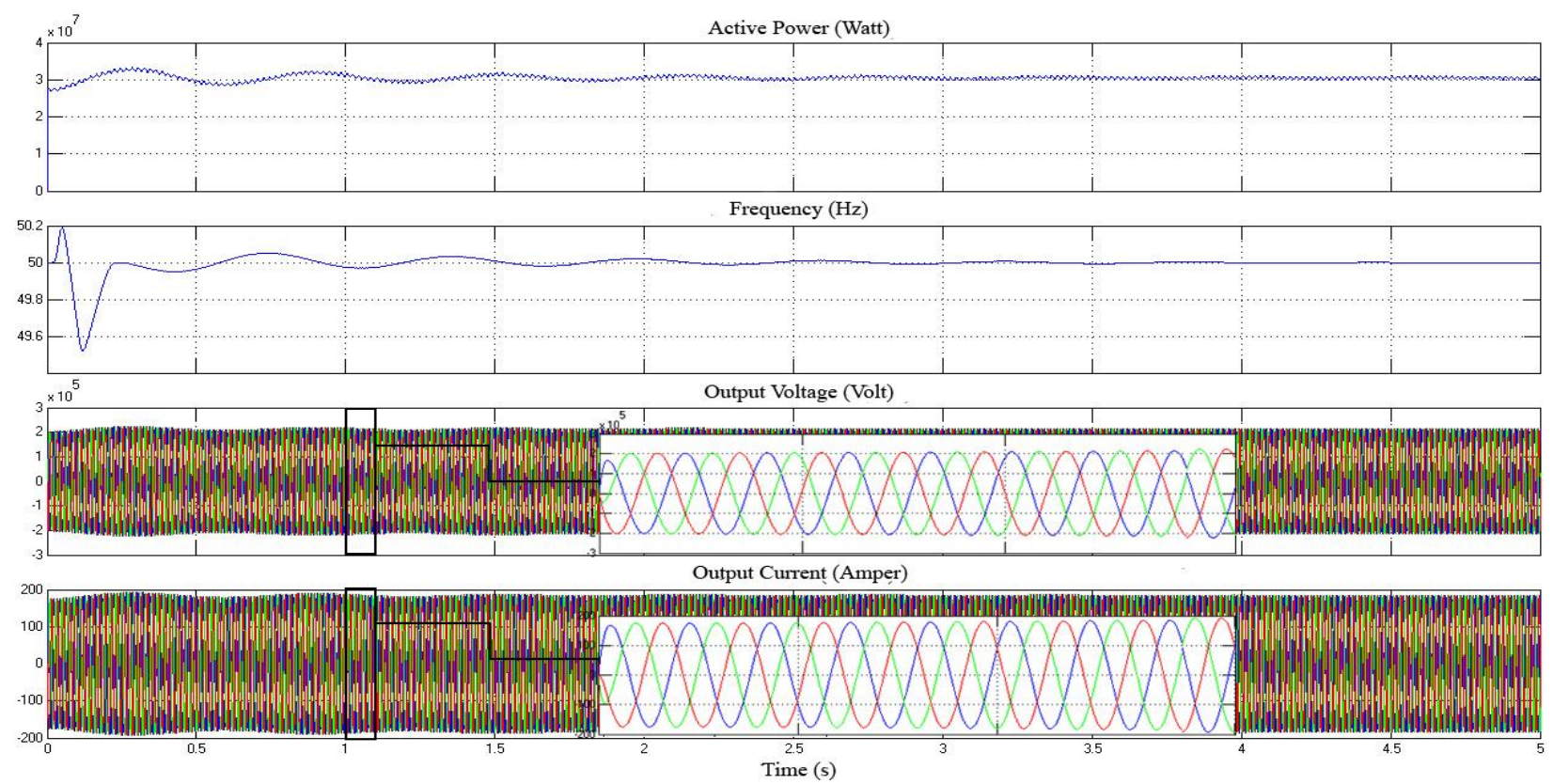

Figure 7. Change in electrical output magnitudes when loaded with HEPP 30,6MW (1,0 pu).

\section{Conclusions}

In this study, a modelling of dynamic behaviour of the system was realized to investigate the changes in output magnitudes (active power, operating frequency, terminal voltage and load current) according to input power of the Adigüzel HEPP. Modelling of dynamic behaviour of HEPP was designed by using the Matlab /Simulink and SimPowerSystems Toolbox. By establishing the same real-time loading conditions of the Adigüzel HEPP in the simulation medium, oscillations in the voltage and frequency were observed. From the obtained frequency-voltage curves, it has been determined that by keeping the excitation circuit voltage-the second input of synchronous generator-constant, oscillations in frequency come with oscillations in terminal voltage only depending on the change in active power. For purpose of limiting these occurring oscillations within the acceptable tolerance value, parameters of the PID controller that controlled the mechanic energy input or turbine speed according to loading statutes were determined. By means of the PID controller that regulated the speed of hydro turbine, operating voltage and frequency reached to desired value in the shortest time and steady and stable working condition of the system was realized. 
Appendices

Table A.1. Hydraulic Turbine and Governor

\begin{tabular}{|c|c|c|}
\hline \multicolumn{2}{|l|}{ Type } & $\begin{array}{c}\text { Vertical shaft } \\
\text { Francis }\end{array}$ \\
\hline \multirow{3}{*}{ Effective head } & Max. & $132.80 \mathrm{~m}$. \\
\hline & Nor. & $116.00 \mathrm{~m}$. \\
\hline & Min. & $84.30 \mathrm{~m}$. \\
\hline \multicolumn{2}{|c|}{ Output at normal head } & $31.375 \mathrm{~kW}$ \\
\hline \multicolumn{2}{|c|}{ Discharge at normal head } & $30 \mathrm{~m}^{3} / \mathrm{s}$ \\
\hline \multicolumn{2}{|c|}{ Revolving speed } & $300 \mathrm{rpm}$ \\
\hline \multicolumn{2}{|c|}{ Water starting time $\left(T_{W}\right)$} & $1.4047 \mathrm{~s}$ \\
\hline \multicolumn{2}{|c|}{ Permanent droop } & 0.05 \\
\hline \multicolumn{2}{|c|}{ Servo gain $\left(K_{a}\right)$} & 3.3 \\
\hline \multicolumn{2}{|c|}{ Servo time constant $\left(T_{a}\right)$} & $0.07 \mathrm{~s}$ \\
\hline
\end{tabular}

Table A.2. Three Phase Transformer Parameters

\begin{tabular}{clc}
\hline Nominal Power & & $36 \mathrm{MVA}$ \\
Rated frequency & & $50 \mathrm{~Hz}$ \\
Winding 1 & Connection & $\mathrm{D} 11$ \\
parameters & Rated voltage & $13.8 \mathrm{kV}$ \\
(ABC & Rated current & $1506 \mathrm{~A}$ \\
terminals) & Resistance & $0.0178 \Omega$ \\
& Inductance & $0.00174 \mathrm{H}$ \\
Winding 2 & Connection & Rated voltage \\
parameters & Rated current & $154 \mathrm{kV}$ \\
(abc terminals) & Resistance & $135 \mathrm{~A}$ \\
& Inductance & $0.2172 \mathrm{H}$ \\
\hline
\end{tabular}

\section{References}

[1] Yalçın E, Çam E, Lüy M. "Load frequency control in four-area power systems using PID controller," ELECO' 2010 Electrical - Electronics and Computer Engineering Symposium, Bursa, pp. 72-77, December 2010.

[2] Kundur P, Power System Stability and Control, McGrawHill, New York, 1994.

[3] Gözde H, Kocaarslan İ, Taplamacıoğlu M.C. and Çam E., "The optimization of load-frequency control with particle swarm algorithm in a two area power system," ELECO' 2008 Electrical - Electronics and Computer Engineering Symposium, Bursa, pp. 212216, November 2008.

[4] Culberg J. Negnevitsky M. and Muttaqi K.M. "Fuzzy interference system controller for hydro turbine-generator system." Power Engineering Conference, 1-6, 2007.

[5] Özbay E. and Gencoglu M.T. "Küçük hidroelektrik santrallerde yük-frekans kontrolü." Fırat Üniversitesi Mühendislik Bilimleri Dergisi. 23(2):

119-128, 2011.
Table A.3. Generator Parameters

\begin{tabular}{|c|c|c|}
\hline \multicolumn{2}{|l|}{ Type } & $\begin{array}{c}\text { A.C. synchronous } \\
\text { generator, vertical } \\
\text { shaft }\end{array}$ \\
\hline \multicolumn{2}{|l|}{ Rotor type } & Salient pole \\
\hline \multicolumn{2}{|l|}{ Nominal power } & 36 MVA \\
\hline \multicolumn{2}{|l|}{ Rated power factor } & 0.85 \\
\hline \multicolumn{2}{|l|}{ Rated frequency } & $50 \mathrm{~Hz}$ \\
\hline \multicolumn{2}{|l|}{ Rated voltage } & $13.8 \mathrm{kV}$ \\
\hline \multicolumn{2}{|l|}{ Rated current } & $1506 \mathrm{~A}$ \\
\hline \multicolumn{2}{|l|}{ Rated speed } & $300 \mathrm{rpm}$ \\
\hline \multicolumn{2}{|l|}{ Runaway speed } & $630 \mathrm{rpm}$ \\
\hline \multicolumn{2}{|c|}{ Stator winding resistance } & $0.0141 \Omega$ \\
\hline \multicolumn{2}{|c|}{ Rotor winding resistance } & $0.0857 \Omega$ \\
\hline \multicolumn{2}{|l|}{ Rotor pole pairs } & 10 \\
\hline \multicolumn{2}{|c|}{ Stator winding connection } & Star \\
\hline \multirow{6}{*}{$\begin{array}{l}\text { Reactances based on } \\
\text { rated load and rated } \\
\text { voltage }(\mathrm{pu})\end{array}$} & $X_{d}$ & 0.992 \\
\hline & $X_{d}^{\prime}$ & 0.295 \\
\hline & $X_{d}^{\prime \prime}$ & 0.183 \\
\hline & $X_{Q}$ & 0.687 \\
\hline & $X_{Q}{ }^{\prime \prime}$ & 0.186 \\
\hline & $X_{l}$ & 0.184 \\
\hline \multirow{3}{*}{ Time constants } & $T_{d o}^{\prime}$ & $7.133 \mathrm{~s}$. \\
\hline & $T_{d}^{\prime}$ & $2.123 \mathrm{~s}$. \\
\hline & $T_{a}$ & $0.177 \mathrm{~s}$. \\
\hline
\end{tabular}

[6] Dongsheng W., Qing Y. and Dazhi W, "A novel PSO-PID controller application to bar rolling process," CCC' 2011 Chinese Control Conference, Yantai, China, pp. 2036-2039.

[7] Saadat H., Power System Analysis, McGraw-Hill Series, 1999.

[8] Machowski, J., Bialek, J.W. and Bumby, J.R. Power Systems Dynamics, John Wiley \& Sons, 2nd ed. United Kingdom; 2008.

[9] Scherer L.G, de Camargo R.F,"Frequency and voltage control of micro hydro power stations based on hydraulic turbine's linear model applied on induction generators," COBEP' 2011 Power Electronics Conference, Brazilian, pp. 546-552.

[10] Working Group on Prime Mover and Energy Supply Models for System Dynamic Performance Studies, "Hydraulic turbine and turbine control models for system dynamic studies," IEEE Transactions on Power Systems, vol. 7, no. 1, pp. 167-179, Febr. 1992. 